\title{
CORRESPONDENCE,
}

\section{ON A NOTATION TO BE USED IN LIFE ASSURANCE COMPUTATIONS.}

To the Editor of the Assurance Magazine.

SIR,-Perhaps it is not void of interest to the readers of the Magazine, to take notice of a proposal of notation in life assurance computations, which has been agreed upon last autumn by some German actuaries. I believe it is just as much felt with you as it is with us, how disagreeable it is that different symbols are used by different anthors for the same expression, and different meanings are given to the same symbol by different authors. It would be very desirable to have uniform symbols for life assurance computations, and we have tried to obtain it, at least for the most common and constantly used expressions. We perfeetly know that the proposed way of notation is not always so simple as we should wish it to be, but it having been our principal object to make it agree with mathematical notation, we have laid principal stress upon the functional notation, thas facilitating the use of analytical methods of computation. As far as possible we have subordinated our selection of the symbols to the notation already in use principally in Germany, but we considered it of absolute necessity to reject as a symbol for life assurance computation any letter which has a generally acknowledged meaning in mathematics, for even those mathematical forms which until now do not enter in life assurance investigations may very likely be employed as soon as our computations are becoming of a more analytical form. Thus, $\pi$ as the proportion of the diameter to the cireumference of the circle, $e$ as the base of the natural logarithmic system, $d$ as the symbol of differentiation, $l$ as the abbreviation of log. nat., $i$ equal to $\sqrt{-1}$, were positively exelnded. I annex a translation of the proposal, and some remarks added to it, and am,

$$
\begin{gathered}
\text { Sir, } \\
\text { Yours most obediently, } \\
\text { WILHELM LAZARUS. } \\
\begin{array}{c}
\text { Proposal for the adoption of uniform symbols in life assurance } \\
\text { computations. }
\end{array}
\end{gathered}
$$

It is willingly acknowledged that the want of nuiformity in the symbols ased in life assurance computations is exceedingly disagreeable. Every 
new work which touches this branch requires a new study of its notation; and this study becomes the more difficult, as a small collection of symbols is employed with constantly changing significations.

It is very desirable that the most common expressions obtain a fixed notation, used by all anthors, and the following proposal is therefore recommended for general adoption.

We have made it a leading point in our proposal that the notation being of mathematical nature, should agree as much as possible with the mathematical system of notation, and that those letters which have a fixed meaning for the mathematician, as $e, i, d, l, \pi, \Delta, \Sigma$, \&c., cannot be allowed to be employed with another meaning. We have tried to give to those expressions which are most frequently used a most simple symbol.

All expressions dependent on age are expressed as functions of the age.

The proposal is limited to those expressions most commonly in use.

$\S 1$. The age is denoted by $a, a+1, a+2, \ldots a+h$; and the general symbol for a variable age is $x, x+1, \ldots x+h$.

$\$ 2$. The number of persons alive taken from the table of mortality is $\lambda$, as a function of the age $\lambda(a) \lambda(a+1) \ldots \lambda(x) \lambda(x+1) \ldots$ (not in the form $\lambda_{x} \lambda_{a}$, where the age is annexed as an index). As the number of persons alive at any age is proportionate to the number of births to which the table refers, it is desirable to have an adequate form of notation. Be $G$ the number of births, and $L(x)$ defined by the equation $G . L(x)=\lambda(x)$, then $L(x)$ is the number alive at the age $x$, supposing the number born to be 1. The number dying in a year is $\lambda(x)-\lambda(x+1), L(x)-L(x+1)$, equal to $-\Delta \lambda(x)$ and $-\Delta L(x)$, also to be denoted by $\tau(x)$ and $T(x)$.

3. Simple notations are recommended for the probabilities of living or dying in a certain time. They are-

$$
\begin{aligned}
& \mathrm{W}(x)=\frac{\lambda(x+1)}{\lambda(x)}=\frac{\mathrm{L}(x+1)}{\mathrm{L}(x)} ; \mathrm{W}(x+1)=\frac{\lambda(x+2)}{\lambda(x+1)}=\frac{\mathrm{L}(x+2)}{\mathrm{L}(x+1)} \\
& \mathrm{W}^{2}(x)=\mathrm{W}(x) \mathrm{W}(x+1)=\frac{\lambda(x+2)}{\lambda(x)}=\frac{\mathrm{L}(x+2)}{\mathrm{L}(x)} \\
& \mathrm{W}^{\mathrm{h}}(x)=\mathrm{W}(x) \mathrm{W}(x+1) \mathrm{W}(x+2) \ldots \mathrm{W}(x+h-1)=\frac{\lambda(x+h)}{\lambda(x)}=\frac{\mathrm{L}(x+h)}{\mathrm{L}(x)}
\end{aligned}
$$

The probability of dying is denoted by $v$, defined by the equation

$$
1=W^{h}(x)+w^{k}(x) \text {. }
$$

$\S 4$. The expectation of life exactly expressed by $\int_{a} \frac{\mathrm{L}(x) d x}{\mathrm{~L}(a)}$, and approximately by $\frac{1}{2}+\frac{\mathrm{L}(a+1)+\mathrm{L}(a+2)+\mathrm{L}(a+3)+\ldots \cdots}{\mathrm{L}(a)}$ is denoted by $\mathbf{E}(a)$.

\$5. Unity with one year's interest added is denoted by $r$ (say $r=1,03$ ); to avoid the negative exponents, unity disconnted for one year is denoted by $\rho$ equal to $\frac{1}{r}$.

$\$ 6$. The present value of an annuity of 1 payable yearly, the first payment to be made directly, is denoted by $R$ as a function of the age $\mathrm{R}(a), \mathrm{R}(\boldsymbol{x})$ (the age not to be annexed as an index). If the first payment

VOL. XII. 
of the annuity is deferred $1,2, \ldots n$ years, the function is denoted by ${ }^{1} \mathrm{R}(x),{ }^{2} \mathrm{R}(x), \ldots .{ }^{n} \mathrm{R}(x)$, the number of years deferred annexed at the top of the $\mathbf{R}$ on the left side. If the annuity is a temporary one for 1, 2, $\ldots t$ years, the function is $\mathrm{R}_{1}(x), \mathrm{R}_{2}(x), \ldots \mathrm{R}_{t}(x)$, the number of years annexed at the foot of the $\mathrm{R}$, on the right side. Accordingly ${ }^{n} \mathrm{R}_{t}(x)$ is the value of a temporary annuity of $t$ years duration, deferred $n$ years. If the annuity is payable half-yearly, monthly, quarterly, $\frac{2}{2}, \frac{4}{4}, \frac{12}{12}$, is annexed at the top of the $\mathrm{R}$, on the right side, $\mathrm{R}^{\frac{2}{2}}(x), \mathrm{R}^{\frac{12}{1} \frac{2}{2}}(x),{ }^{n} \mathrm{R}^{\frac{4}{4}}(x)$, \&c.

§ 7. The single premium (present value) for the assurance of the capital 1 , payable at the end of the year when death occurs, is denoted by $P$, as a function of the age $P(x)$; the annual premium payable for the whole term of life is $p(x)$. If the assurance is a temporary one for $1,2, \ldots t$ years only, or a deferred one (beginning in $1,2, \ldots n$ years), the function is denoted in conformity to $\$ 6$.

$$
\begin{aligned}
& \mathbf{P}_{1}(x), \mathrm{P}_{2}(x), \ldots \mathrm{P}_{t}(x), \text { and } p_{1}(x), p_{2}(x), \ldots p_{t}(x) \\
& { }^{3} \mathrm{P}(x),{ }^{2} \mathrm{P}(x), \ldots{ }^{n} \mathrm{P}(x), \text { and }{ }^{1} p(x),{ }^{2} p(x), \ldots{ }^{n} p(x)
\end{aligned}
$$

If the preminm is payable half-yearly, quarterly, monthly, the annual

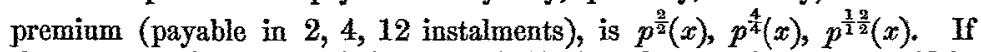
the assurance is for the whole term of life, bnt the preminm to be paid in $m$ annual payments, the amnual premium is denoted by ${ }_{(m)} p(x)$, defined by the equation $(m) p(x)=\frac{P(x)}{R_{m}(x)}$.

$\S 8$. The preminas for the assurance of an endowment is denoted by German letters; the single preminm, if the endowment is deferred $n$ years, by "筹 $(x)$, the annual premium by " $\mathrm{p}(x)$.

89. The valnes of annities for two joint lives aged $a_{2}$ and $a+h$ are denoted by

$\mathrm{R}(a, a+h)$ if the annuity is payable only during the joint duration of both lives,

$\mathrm{R}\left(\frac{a}{a+h}\right)$ if the annuity is payable only after death of the person aged

$a+h$ years, the person aged $a$ being still alive.

$\S 10$. In conformity to $\S 9$ the premium for the assurance of joint lives is denoted by

$\mathrm{P}(a, a+h), p(a, a+h$, assurance payable at the death of the first of both dying;

$\mathrm{P}\left(\frac{a}{a+h}\right), p\left(\frac{a}{a+h}\right)$, survirorship assurance payable at the death of the person aged $(a+h)$, the person aged $a$ surviving.

Dr. PH. Fischer, Darmstadt.

Dr. K. HeYM, Leipzig.

G. Hopf, Gotha.

WilHelm Lazarus, Hamburg.

Dr. LaUd, Trieste.

Prof. Wentwaer, Pesth.

Dr. A. WIEGAND, Halle.

Prof. Dr. Wittstein, Hanover.

October, 1863.

Dr. A. ZluLmer, Stettin. 


\section{Remarks.}

At $\$ 2$. It ought to be mentioned that all numbers in tables of mortality are proportionate numbers only, and that it might have been sufficient in the notations to have had regard to this peculiarity. Bnt it was diffcult to determine a fixed point in the tables of mortality, which do not always begin at birth, and therefore it has been considered advisable to introduce both notations, $\lambda(x)=\mathrm{GL}(x)$ and $r(x)=\mathrm{G}^{\prime} \mathrm{T}(x)$. That in all cases where the numbers in the table of mortality are used to determine a probability, and appear in the numerator as well as in the denominator, it need scarcely to be mentioned, it is optional to use $\lambda$ or $\mathrm{L}, \tau$ or $\mathrm{T}$.

$A t \S 3$. One year has been adopted as the unit of time in the probabilities of living or dying during a fixed period. The same form of notation is used for shorter periods than a year; thus, $W^{\frac{1}{2}}(x)$ denotes the probability for a person aged $x$ years living six months, wo the probability of dying in the next moment.

At $\S 6$. It would be very desirable to hare a short expression in words for the valne of an annuity of 1 payable during the whole term of life annually, the first payment just due. The expression, "Mise," used by many authors, is recommended.

It will not be uninteresting to see some formula expressed by the new symbols:-

$$
\begin{aligned}
\mathrm{R}_{1}(x)=1 ;{ }^{1} \mathrm{R}_{1}(x)=W(x) \rho ;{ }^{2} \mathrm{R}_{1}(x)=W^{2}(x) \rho^{2} ;{ }^{3} \mathrm{R}_{1}(x)=\mathrm{W}^{3}(x) \rho^{3} \ldots \\
\mathrm{R}(x)=\frac{\mathrm{L}(x) \rho^{x}+\mathrm{L}(x+1) \rho^{x+1}+\mathrm{L}(x+2) \rho^{x+2}+\ldots}{\mathrm{L}(x) \rho^{x}} \\
\mathrm{R}(x)=\mathrm{R}_{1}(x)+{ }^{1} \mathrm{R}_{1}(x)+{ }^{2} \mathrm{R}_{1}(x)+{ }^{3} \mathrm{R}_{1}(x)+\ldots . \\
\mathrm{R}(x)=\mathrm{R}_{1}(x)+{ }^{1} \mathrm{R}_{1}(x)+{ }^{2} \mathrm{R}_{1}(x)+\ldots .{ }^{t} \mathrm{R}_{1}(x) \\
{ }^{t} \mathrm{R}(x)={ }^{t} \mathrm{R}_{1}(x)+{ }^{t+1} \mathrm{R}_{1}(x)+{ }^{t+2} \mathrm{R}_{1}(x)+\ldots . .=\mathrm{W}^{t}(x) \rho^{t} \mathrm{R}(x+t) \\
\mathrm{R}(x)=\mathrm{R}_{2}(x)+{ }^{t} \mathrm{R}(x) .
\end{aligned}
$$

If the annuity is payable momently,

$$
\mathrm{R}^{\frac{\infty}{\infty}}(x)=\int_{a} \frac{\stackrel{\infty}{\mathrm{L}}(x) \rho^{x} d^{x}}{\mathrm{~L}(a) \rho^{a}}
$$

At $\$ 7$. From the well-known equation

it follows

$$
{ }^{1} \mathrm{R}(x)+\left(1+\frac{1}{r-1} \mathrm{P}(x)\right)=\frac{1}{r-1}
$$

$$
\begin{aligned}
& \mathrm{P}(x)=\rho-(1-\rho)^{1} \mathrm{R}(x)=1-(1-\rho) \mathrm{R}(x) \\
& p(x)=\frac{\mathbf{P}(x)}{\mathbf{R}(x)} \quad{ }^{n} p(x)=\frac{n}{n} \mathbf{P}(x)_{{ }^{n}(x)} p_{t}(x)={\frac{\mathbf{P}(x)}{\mathbf{R}_{t}(x)}}_{(m)} p(x)=\frac{\mathrm{P}(x)}{\mathbf{R}_{m}(x)} .
\end{aligned}
$$

$\mathrm{P}(x+n)-p(x) \mathrm{P}(x+n)$ is the surrender value of a policy for an assurance after $n$ year's duration, of which the annual net premium is $p(x)$ when the $(n+1)$ th preminm is just dne but anpaid, $\mathrm{P}(x+n)-p(x)^{1} \mathrm{P}(x+n)$ if the $(n+1)$ th premium has just been paid.

$\mathrm{P}(x+n)$ being equal to $p(x+n) \mathrm{R}(x+n)$, this valne becomes $\{p(x+n)-p(x)\} \mathbf{R}(x+n)$ and $\{p(x+n)-p(x)\} \mathrm{R}(x+n)+p(x)$, or, 
according to the notation introduced in mathematics by Moigno, $\left.\mathrm{R}(x+n)\right|_{x} ^{x+n} p(x)$ and $p(x)+\left.\mathrm{R}(x+n)\right|_{x} ^{x+n} p(x)$.

This value changes if the next payment is due in the time $t$; it changes if an annual premium only for $m$ years is charged instead of a preminm for the whole term of life. It is evident that the value of a policy depends on so many different circumstances that they cannot be expressed in one single symbol. But perhaps it is convenient to express this value as a function of the net premitum (symbol of the function, $\phi$ ), adding the time elapsed since the policy was taken at top left hand, and the time till the next payment of premium at the foot right hand. This last addition ceases when either no further payment of premium is required, or when the next payment is due immediately, viz.:-

$$
\begin{aligned}
& { }^{n} \phi\{p(x)\}=\mathrm{P}(x+n)-p(x) \mathrm{R}(x+n) \\
& { }^{n} \phi_{1}\{p(x)\}=\mathrm{P}(x+n)-p(x)^{1} \mathrm{R}(x+n) \\
& { }^{n} \phi\{p(x)\} ;{ }^{n} \phi\{(m) p(x)\} ;{ }^{n} \phi\{\mathrm{P}(x)\}=\mathrm{P}(x+n)
\end{aligned}
$$

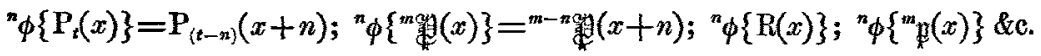

$$
\begin{aligned}
& \text { At } \S 8 . \quad{ }^{n} g(x)=W^{n}(x) \rho^{n}={ }^{n} R_{1}(x) \\
& " p(x)=\frac{\text { 籍 }(x)}{\mathrm{R}_{n}(x)} \text {. }
\end{aligned}
$$

At $\S 9$. As a symbol for the value of an annuity for two persons payable till both have died, the age being $a$ and $a+h, \mathrm{R}(a / / a+h)=$ $\mathrm{R}(a)+\mathbf{R}(a+h)-\mathbf{R}(a, a+h)$ is recommended.

WILHELM LAZARUS.

\section{THE DEMONSTRATION OF CERTAIN FORMULE.}

To the Editor of the Assurance Magazine.

SrR,-I beg to submit demonstrations of several of the formulæ for whole life, temporary, deferred, and endowment assurances.

Let $(a)$ denote the value of an annuity of $f 1$ on the joint lives of the last $v$ survivors of the lives $m, m_{1}, m_{2}$, \&c.; and (A) the value of an assurance of $£ 1$ on the same lives.

The present value of a perpetuity of $\mathfrak{E} 1$ per annum, the first payment dne immediately, is made up of the present value of an annuity of $f 1$ during the continuance of a given status, and the present value of a reversionary annuity of $\mathrm{fl}$ to commence at the end of the year in which the status ceases, which latter annuity is equivalent to the present value of an assurance of $£ 1+\frac{1}{i}$. Now, the reversionary annuity of $£ 1$ can be secured by an assurance of $£ 1+\frac{1}{i}$ dnring a certain term, together with an endowment of the same sum payable at the end of that term.

Hence, the value of a perpetuity of $\mathfrak{f 1}$, first payment immediate, equals the present value of a temporary annuity for $t$ years on the joint lives of the last $v$ survivors + present value of an assurance for $t$ years of $£ 1+\frac{1}{i}$ on the failure of the joint existence of the last $v$ survivors + present value of 